\title{
Crescimento demográfico e espacial de uma cidade média: Angra dos Reis
}

Michael Chetry ${ }^{2}$

\section{RESUMO}

A cidade de Angra dos Reis, localizada na região da Baía da llha Grande, a $150 \mathrm{~km}$ ao sul do Rio de Janeiro, é uma das primeiras ocupações coloniais do litoral fluminense. Durante quase 400 anos, ela era caracterizada por um fraco dinamismo demográfico, até meados do século XX, data a partir da qual o município mostra um ritmo de crescimento demográfico intenso e regular. Hoje a cidade conta com quase 200 mil habitantes, o que a torna estatisticamente uma cidade média. O objetivo deste artigo é descrever e analisar o crescimento demográfico de Angra dos Reis, seus componentes e seus impactos na extensão da malha urbana. Essa dinâmica é o resultado de uma forte imigração, embora seu papel venha diminuindo nos últimos anos. O crescimento urbano da cidade apresenta um aspecto fragmentado ao longo do litoral e sublinha o caráter desigual do processo de urbanização brasileira, entre melhoria geral das condições urbanas e a expansão dos aglomerados subnormais.

PALAVRA-CHAVE: Crescimento urbano; Demografia; Migração; Cidade média; Angra dos Reis

\begin{abstract}
The city of Angra dos Reis, located in the Ilha Grande Bay region, $150 \mathrm{~km}$ south of Rio de Janeiro, is one of the first colonial occupations of the Rio de Janeiro coast. For almost 400 years, it was characterized by a weak demographic dynamism until the middle of the twentieth century, from which the municipality shows an intense and regular demographic growth rate. Today the city has almost 200 thousand inhabitants, which makes it statistically an average city. The purpose of this paper is to describe and analyze the demographic growth of Angra dos Reis, its components and its impacts on the extension of the urban network. This dynamic is the result of strong immigration, although its role has been diminishing in recent years. The urban growth of the city has a fragmented aspect along the coast and underlines the uneven character of the Brazilian urbanization process, between general improvement of urban conditions and the expansion of subnormal agglomerations.
\end{abstract}

KEYWORDS: Urban growth; Demography; Migration; Middle city; Angra dos Reis

\section{1- Introdução}

Localizado na região da Baía da llha Grande, a 150 km ao sul do Rio de Janeiro, o município de Angra dos Reis reúne hoje quase 200 mil habitantes, o que a classifica estatisticamente na categoria das cidades médias $^{3}$. Embora tenha sido uma das primeiras ocupações do litoral fluminense no período colonial,

1 Agradeço aos meus colegas Ricardo Dantas, Frederico Policarpo, Licio Monteiro e aos pareceristas da revista pela releitura atenta do texto e pelas sugestões formuladas.

2 Professor Adjunto de Geografia do Departamento de Geografia e Políticas Públicas da Universidade Federal Fluminense (IEAR/UFF). Doutor em Geografia pela Université Jean Moulin Lyon 3 (França). É vicecoordenador do Grupo de Estudos da Baía da Ilha Grande (GEBIG/UFF). Pesquisa cidades e sociedades urbanas, particularmente no Brasil, atuando principalmente nos seguintes temas: segregação, fragmentação e desigualdades sócio-espaciais; transformações contemporâneas dos espaços urbanos; práticas e representações espaciais; política e planejamento urbanos.

3 Cidades com população entre 100 mil e 500 mil habitantes de acordo com o IBGE. Existe um intenso debate sobre a definição de cidade média no qual não cabe entrar aqui. Mas, de forma resumida, aponta a necessidade de ir além do simples critério de tamanho populacional e levar em conta o papel e as funções que essa cidades desempenham na rede urbana. Sobre este debate ver, por exemplo, Sposito (2007). 
o crescimento demográfico começou realmente a partir da década de 1950, e deve muito às políticas econômicas nacionais que corresponderam à implantação de uma série de grandes empreendimentos industriais na cidade e, em seguida, ao desenvolvimento da atividade turística.

Se o caso de Angra dos Reis não difere daquele das cidades de mesmo porte, cujo crescimento é sustentado nas últimas décadas, o seu dinamismo demográfico é mais antigo e mais intenso, e sobretudo se mantem elevado depois dos anos 1980 quando o crescimento médio das cidades brasileiras se reduz significativamente. Por outro lado, esse forte crescimento demográfico particularmente estável, ocasionou profundas transformações do espaço urbano.

Neste contexto, o objetivo deste estudo é descrever e compreender a dinâmica populacional e urbana de Angra dos Reis desde meados do século XX. Para isso analisaremos vários indicadores demográficos e urbanos do município calculados com base nos dados dos censos demográficos do IBGE realizados desde 1940. O texto é dividido em três seções além dessa introdução e das considerações finais. Na primeira seção, descreveremos o crescimento demográfico da cidade e seus ritmos. A estreita relação do dinamismo demográfico da cidade com seu dinamismo econômico, nos conduzirá a nos interessar na segunda seção ao papel preponderante das migrações neste crescimento. Enfim, essa interrogação sobre a amplitude do crescimento da cidade nós levará a nos concentrar na terceira seção sobre a dinâmica urbana de Angra dos Reis.

\section{2- Um crescimento demográfico intenso e regular}

Até os meados do século XX, o município de Angra dos Reis se caracterizou pelo seu fraco dinamismo demográfico (Gráfico 1). Entre 1872 e 1940, sua população permanece em torno de 20 mil habitantes e parece até ter experimentado uma fase de decrescimento de 1872 a 1920. Este período de estagnação demográfica é a consequência direta da crise econômica que afetou Angra dos Reis a partir do meio do século XIX. Nesta época, a cidade dependia principalmente da sua atividade portuária através da exportação de café e também do tráfico de escravos, que tornou o porto de Angra o segundo maior do Brasil meridional (Machado, 1995). Com isso, iniciou-se o processo de urbanização de Angra dos Reis que ganhou o estatuto de cidade em 1835. No final do século XIX, um conjunto de fatores enfraqueceu a função portuária de Angra e contribuiu para a recessão da economia local: a construção da linha férrea Pedro Il em 1877, que liga diretamente Rio de Janeiro a São Paulo pelo Vale do Paraíba, marginalizando o porto de Angra como ponto de escoamento das produções; a decadência da cultura do café na região; e a proibição do comércio de escravos decorrente da Lei Eusébio de Queirós, de 1850. A partir daí, a economia local ficou reduzida à agropecuária (cultivo de bananas e principalmente agricultura de subsistência) e à pesca, atividade tradicional, mas pouco dinâmica.

\section{Gráfico 1: Evolução da população de Angra dos Reis em número de habitantes (1872-2015)}

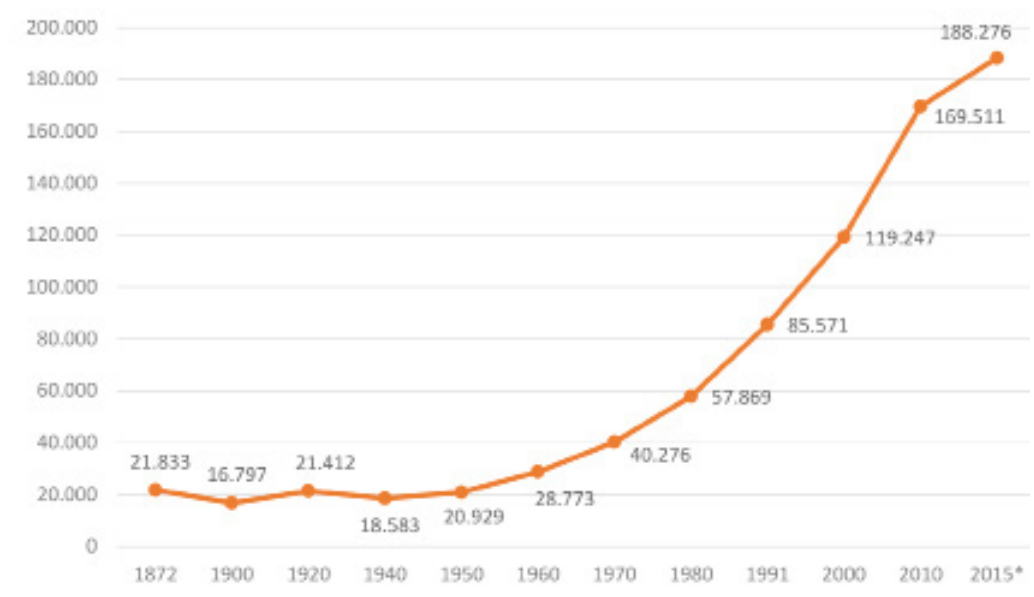

Fonte: IBGE, Censos demográficos.

* Estimativa população 2015 
No final da Primeira República (1930), Angra dos Reis começou a sair do seu isolamento das décadas anteriores com a reforma do porto e a construção da estrada de ferro que o liga ao oeste de Minas Gerais. Os efeitos dessas obras serão sobretudo expressivos a partir dos anos 1940, com a inauguração da Companhia Siderúrgica Nacional (CSN) na cidade vizinha de Volta Redonda, e para qual o porto de Angra assegurou o abastecimento em matérias primas e escoamento da produção de aço (Machado, 1995). Com a recuperação das suas funções portuárias e comerciais, a dinâmica demográfica de Angra dos Reis renasceu timidamente: a população aumentou em 2,4 mil habitantes entre 1940 e 1950 voltando ao seu tamanho de população do início do século. O crescimento da cidade se tornou significativo, com uma taxa de 1,2\% por ano, embora bem inferior ao crescimento das outras cidades da região e da população do estado e do país (Tabela 1). Este período correspondeu também a um processo de restruturação e de revitalização do núcleo urbano original em torno do porto (Abreu, 2005).

Tabela 1: Taxa de crescimento anual médio Angra dos Reis, Barra Mansa, Volta Redonda, Resende, Estado do Rio de Janeiro, Brasil (1940-2015)

\begin{tabular}{|c|c|c|c|c|c|c|}
\hline Período & Angra dos Reis & Barra Mansa & Volta Redonda & Resende & $\begin{array}{c}\text { Estado do Rio de } \\
\text { Janeiro }\end{array}$ & Brasil \\
\hline $1940-1950$ & $1,2 \%$ & $2,8 \%$ & - & $2,4 \%$ & $2,6 \%$ & $2,3 \%$ \\
\hline $1950-1960$ & $3,2 \%$ & $6,2 \%$ & $9,5 \%$ & $3,5 \%$ & $3,7 \%$ & $3,2 \%$ \\
\hline $1960-1970$ & $3,4 \%$ & $4,8 \%$ & $3,5 \%$ & $3,2 \%$ & $3,1 \%$ & $2,9 \%$ \\
\hline $1970-1980$ & $3,7 \%$ & $4,3 \%$ & $3,9 \%$ & $2,7 \%$ & $2,3 \%$ & $2,5 \%$ \\
\hline $1980-1991$ & $3,6 \%$ & $1,0 \%$ & $1,7 \%$ & $0,4 \%$ & $1,1 \%$ & $1,9 \%$ \\
\hline $1991-2000$ & $3,8 \%$ & $-0,1 \%$ & $1,1 \%$ & $1,5 \%$ & $1,2 \%$ & $1,5 \%$ \\
\hline $2000-2010$ & $3,6 \%$ & $0,4 \%$ & $0,6 \%$ & $1,4 \%$ & $1,1 \%$ & $1,2 \%$ \\
\hline $2010-2015^{*}$ & $2,1 \%$ & $0,3 \%$ & $0,5 \%$ & $1,0 \%$ & $0,7 \%$ & $1,4 \%$ \\
\hline
\end{tabular}

Fonte: IBGE, Censos demográficos. * Estimativa população 2015

A partir dos anos 1950, observou-se uma mudança radical da dinâmica demográfica da cidade de Angra dos Reis, quando se abriu um longo período de 60 anos de crescimento demográfico intenso e ininterrupto (Gráfico 1). Este forte incremento populacional coincidiu com a consolidação do processo de industrialização no país e a inserção de Angra no projeto nacional desenvolvimentista. Os números são vertiginosos: entre 1950 e 2010, a população de Angra dos Reis foi multiplicada por 8, passando de $21 \mathrm{mil}$ a 170 mil habitantes, o que representa a duplicação da população a cada vinte anos. Se os dados mostram a velocidade do crescimento demográfico da cidade, cabe também apontar sua estabilidade ao corresponder a uma taxa de crescimento anual compreendida entre 3,2 \% e 3,6\% ao longo do período 1950-2010 (Tabela 1).

O crescimento do município se tornou, assim, superior às taxas de crescimento médio do estado e do país, tendo ambas diminuído fortemente desde os anos 1960. Até os anos 1980, seu crescimento também superou aquele das cidades brasileiras de tamanho comparável, entre 20 mil e 50 mil habitantes, que cresceram apenas 0,5\% por ano, sendo mais próximo daquele das cidades de tamanho superior (Tabela 2). Isto testemunha a intensidade do crescimento da população de Angra e sua relativa precocidade em relação às cidades de mesmo tamanho. No entanto, ao comparar com as principais cidades da região, Angra registrou ainda neste período um crescimento inferior a Barra Mansa e Volta Redonda, embora se aproximando das taxas de crescimento dessas cidades que, aliás, diminuem desde os anos 1960.

Tabela 2: Taxa de crescimento anual médio segundo o tamanho dos municípios (1960-2015)

\begin{tabular}{|c|c|c|c|c|c|c|}
\hline Classe de Cidades & $\mathbf{1 9 6 0 - 1 9 7 0}$ & $\mathbf{1 9 7 0 - 1 9 8 0}$ & $\mathbf{1 9 8 0 - 1 9 9 1}$ & $\mathbf{1 9 9 1 - 2 0 0 0}$ & $\mathbf{2 0 0 0 - 2 0 1 0}$ & $\mathbf{2 0 1 0 - 2 0 1 5}^{*}$ \\
\hline Menos de 20.000 & $3,9 \%$ & $-0,4 \%$ & $1,1 \%$ & $1,7 \%$ & $-0,3 \%$ & $-0,1 \%$ \\
\hline De 20.001 a 50.000 & $0,6 \%$ & $0,5 \%$ & $0,6 \%$ & $0,2 \%$ & $0,9 \%$ & $1,1 \%$ \\
\hline
\end{tabular}




\begin{tabular}{|c|c|c|c|c|c|c|}
\hline Classe de Cidades & $\mathbf{1 9 6 0 - 1 9 7 0}$ & $\mathbf{1 9 7 0 - 1 9 8 0}$ & $\mathbf{1 9 8 0 - 1 9 9 1}$ & $\mathbf{1 9 9 1 - 2 0 0 0}$ & $\mathbf{2 0 0 0 - 2 0 1 0}$ & $\mathbf{2 0 1 0 - 2 0 1 5}$ \\
\hline De 50.001 a 100.000 & $1,0 \%$ & $4,1 \%$ & $1,9 \%$ & $1,0 \%$ & $0,6 \%$ & $1,7 \%$ \\
\hline De 100.001 a 500.000 & $4,8 \%$ & $4,5 \%$ & $3,1 \%$ & $2,4 \%$ & $2,1 \%$ & $1,9 \%$ \\
\hline Mais de 500.000 & $5,6 \%$ & $4,9 \%$ & $2,7 \%$ & $2,1 \%$ & $1,8 \%$ & $1,8 \%$ \\
\hline
\end{tabular}

Fonte: IBGE, Censos demográficos.

* Estimativa população 2015

A partir dos anos 1980, o comportamento de Angra dos Reis se diferenciou mais nitidamente das tendências observadas em escalas nacionais e regionais. Assim, entre 1980 e 2010, o ritmo de crescimento de Angra dos Reis se manteve em um nível elevado, em torno de 3,6\% por ano, enquanto as taxas de crescimento do estado e do país caíram para 1,2\% entre 2000 e 2010 e aquele das cidades de mesmo tamanho para 2,1\%. Ademais, supera largamente as outras cidades da região de tamanho comparável que registram uma queda nas suas taxas de crescimento, atingindo um valor inferior a 1,4\%. Assim, em relação às cidades brasileiras ou da região, Angra dos Reis se singularizou, mantendo seu forte dinamismo demográfico.

As estimativas de população do Instituto Brasileiro de Geografia e Estatística (IBGE) realizadas em 2015, parecem indicar uma clara desaceleração do crescimento de Angra dos Reis nos últimos anos: de 3,6\% ao ano entre 2000 e 2010, a taxa de crescimento deveria ter passado para 2,1\% ao ano entre 2010 e 2015, aproximando-se assim do valor do conjunto das cidades de 100 mil a 500 mil habitantes $(1,9 \%)$ no mesmo período. Todavia, o crescimento demográfico de Angra dos Reis permanece muito superior às principais cidades da região e às médias estadual e nacional, testemunhando um dinamismo demográfico ainda importante. Ademais, em termos absolutos, o crescimento de Angra ainda é significativo: com uma previsão de 188.276 habitantes em 2015 , a cidade teria aumentado cerca de 20 mil indivíduos em cinco anos.

\section{3- A contribuição decisiva das migrações no crescimento}

O intenso crescimento demográfico de Angra dos Reis desde meados do século XX, e sua extraordinária estabilidade, se explica pela combinação de dois fatores: os fluxos migratórios e o crescimento natural da população do município. Torna-se difícil avaliar com precisão o peso de cada um desses fatores no crescimento da cidade devido à ausência ou à limitação dos dados nos censos sucessivos. Porém, a entrada do Brasil no processo de transição demográfica a partir dos anos 1960/70, juntamente com a forte diminuição da taxa de mortalidade a partir dos anos 1940 e a diminuição da taxa de natalidade a partir dos anos 1960, contribuiu para a redução da taxa de crescimento natural. De fato, o forte crescimento de Angra dos Reis, a partir dos anos 1950, foi essencialmente o resultado das migrações, tanto por seus efeitos diretos no aumento da população quanto por seus efeitos induzidos sobre o crescimento natural através das mudanças que elas ocasionaram na estrutura demográfica da população.

A chegada de imigrantes em Angra dos Reis não ocorreu de forma regular ao longo do tempo, fazendo com que o peso da migração no crescimento demográfico da cidade variasse de acordo com as épocas. Os fluxos migratórios para Angra dos Reis aumentaram a partir dos anos 1950, mas principalmente nos anos 1960 e 1970 (Tabela 3). O número de imigrantes quadriplicou entre as décadas 1950-1960 e 19701980 passando de 4,2 mil a 16,1 mil. No início dos 1980, a migração para Angra dos Reis alcançou o seu máximo com uma taxa de imigração de quase $30 \%$. Outro dado que expressa a importância dos fluxos de imigração neste período é a proporção dos não naturais de Angra dos Reis no total da população do município que subiu de 19,6\%, em 1960, a 40,5\% em 1980. No Brasil, os anos 1960 e 1970 foram um período de intensos movimentos migratórios do campo para cidade, em sua maioria dirigidos para os estados do Rio de Janeiro e São Paulo, e os grandes centros urbanos de fato vão experimentar forte crescimento demográfico neste período, conforme apresentado na Tabela 2 (Oliveira et al., 2011). Mas, Angra dos Reis se beneficiou também desses movimentos migratórios graças à implantação de uma 
série de grandes empreendimentos a partir do final dos anos 1950 que atraíram e facilitaram a vinda da mão de obra para a cidade. Em 1959, a construção do Estaleiro Verolme, com capital holandês, no quadro do Plano de Metas do Juscelino Kubitschek, animou a economia e o mercado de emprego locais e desenvolveu uma classe operária. Este movimento se ampliou nas décadas seguintes. Nos anos 1970, no período do regime militar, o município se tornou área de Segurança Nacional (1969) e, neste quadro, recebeu importantes investimentos do governo federal com o início do Projeto Nuclear Brasileiro e a construção das Usinas Nucleares Angra I a partir de 1972, e Angra II a partir de 1982. Em seguida, a implantação do Terminal de Petróleo da Baía da Ilha Grande (TEBIG) em 1977 ampliou a oferta de emprego, em particular, para uma mão de obra qualificada ${ }^{4}$. A esses empreendimentos se somou à abertura da BR 101 em 1974, que liga o Rio de Janeiro ao litoral do estado de São Paulo e melhorou o acesso à Angra dos Reis e iniciou uma diversificação dos investimentos e da economia, em particular, através do desenvolvimento do turismo de alto padrão voltado às elites das duas metrópoles nacionais. Assim, entre 1960 e 1980, observou-se a queda do setor agropecuário, que empregava 41,1\% da População Economicamente Ativa (PEA) em 1960 e apenas 9\% em 1980. Reciprocamente, enquanto a indústria era quase inexistente em 1960, concentrando somente $13 \%$ da PEA, seu peso passou a 40,2\% da PEA em 1980. Por outro lado, destaca-se o forte crescimento da proporção da PEA ligada à prestação de serviços no final deste período, passando de 8,4\% em 1970 a 20,8\% em 1980, sendo que a maioria desse ramo é composto por atividades de alojamento, alimentação e domésticas, isto é relacionadas ao desenvolvimento do turismo na região (Bertoncello, 1992).

Tabela 3: Indicadores de imigração em Angra dos Reis (1950-2010)

\begin{tabular}{|c|c|c|}
\hline Período & Número de Imigrantes & Taxa de Imigração \\
\hline $1950-1960$ & 4.204 & $16,9 \%$ \\
\hline $1960-1970$ & 7.573 & $21,9 \%$ \\
\hline $1970-1980$ & 14.288 & $29,1 \%$ \\
\hline $1980-1991$ & 17.282 & $24,2 \%$ \\
\hline $1991-2000$ & 27.914 & $27,3 \%$ \\
\hline $2000-2010$ & 30.777 & $21,3 \%$ \\
\hline
\end{tabular}

Fonte: IBGE, Censos demográficos.

Nas últimas décadas, o ritmo das migrações para a cidade se tornou mais irregular. A partir do final dos anos 1980, observamos a diminuição global do volume da migração em direção ás cidades no país como consequência da crise econômica que o Brasil atravessou nesta década (Oliveira et al., 2011). Angra dos Reis não escapou dos efeitos da crise e as migrações para a cidade marcaram uma desaceleração nos anos 1980, pois a taxa de imigração recuou em $5 \%$ nessa década. Em seguida, esse quadro se reverteu nitidamente quando se observa a forte retomada dos movimentos migratórios para a cidade nos anos 1990 (acréscimo de pouco mais de 10 mil pessoas em relação à década anterior) fazendo com que a taxa de imigração voltasse praticamente ao seu nível mais elevado registrado na década de 1970. Durante esse período ocorreu a retomada da construção da usina nuclear em meados dos anos 1990 que, junto com a ampliação da indústria turística puxada pela desativação do presídio da llha Grande (1994), ofereceram novas possibilidades de emprego em Angra dos Reis. Porém, essa tendência será breve, pois os movimentos migratórios conheceram uma nova desaceleração na primeira década do século XXI. O contingente de imigrantes permaneceu ainda importante com mais de 30 mil imigrantes na década 2000-2010, mas é relativamente pouco em relação ao conjunto da população da cidade. De fato, a taxa de imigração caiu para $21,1 \%$ no período, retornando ao seu nível dos anos 1960. De forma geral, os dados recentes parecem, então, indicar uma tendência de estabilização dos fluxos migratórios em Angra dos Reis nas últimas décadas. A permanência de uma taxa alta de crescimento da cidade ao longo deste período significa que essa diminuição é compensada pelo crescimento natural da população.

4 O estaleiro Verolme empregava em torno 4000 operários na década de 1970. Angra 1 e 2 empregavam em 1982 de 3700 a 10000 operários (Guanziroli apud Santos, 2009). 
Com efeito, os sucessivos fluxos de migração impactaram na estrutura demográfica da população. A análise da evolução da forma da pirâmide etária entre 1980 e 2010 indica um envelhecimento da população de Angra dos Reis (Figura 1). Em 1980, a pirâmide etária de Angra dos Reis é caracterizada como de uma população jovem, com uma base larga que testemunha uma taxa de natalidade alta, e que vai se estreitando à medida que aumentam os grupos de idade. Em 2010, a pirâmide se tornou típica de uma população adulta, os 15-59 anos representando dois terços da população. Também, a proporção dos idosos ganhou importância pois os de mais de 60 anos representam 8,5\% da população e os mais de 50 anos quase $20 \%$.

Figura 1: Pirâmides etárias de Angra dos Reis em 1980, 1991, 2000 e 2010
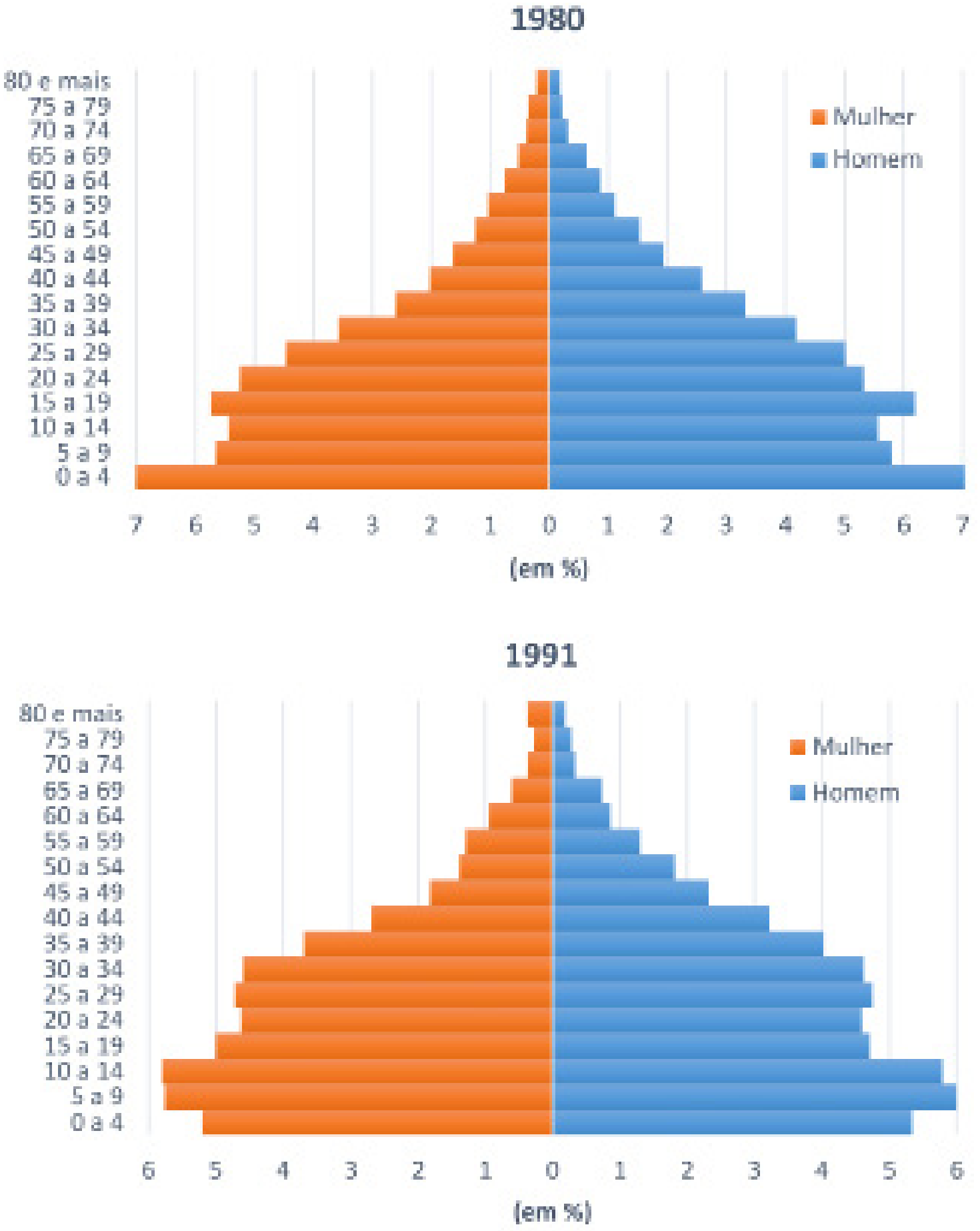

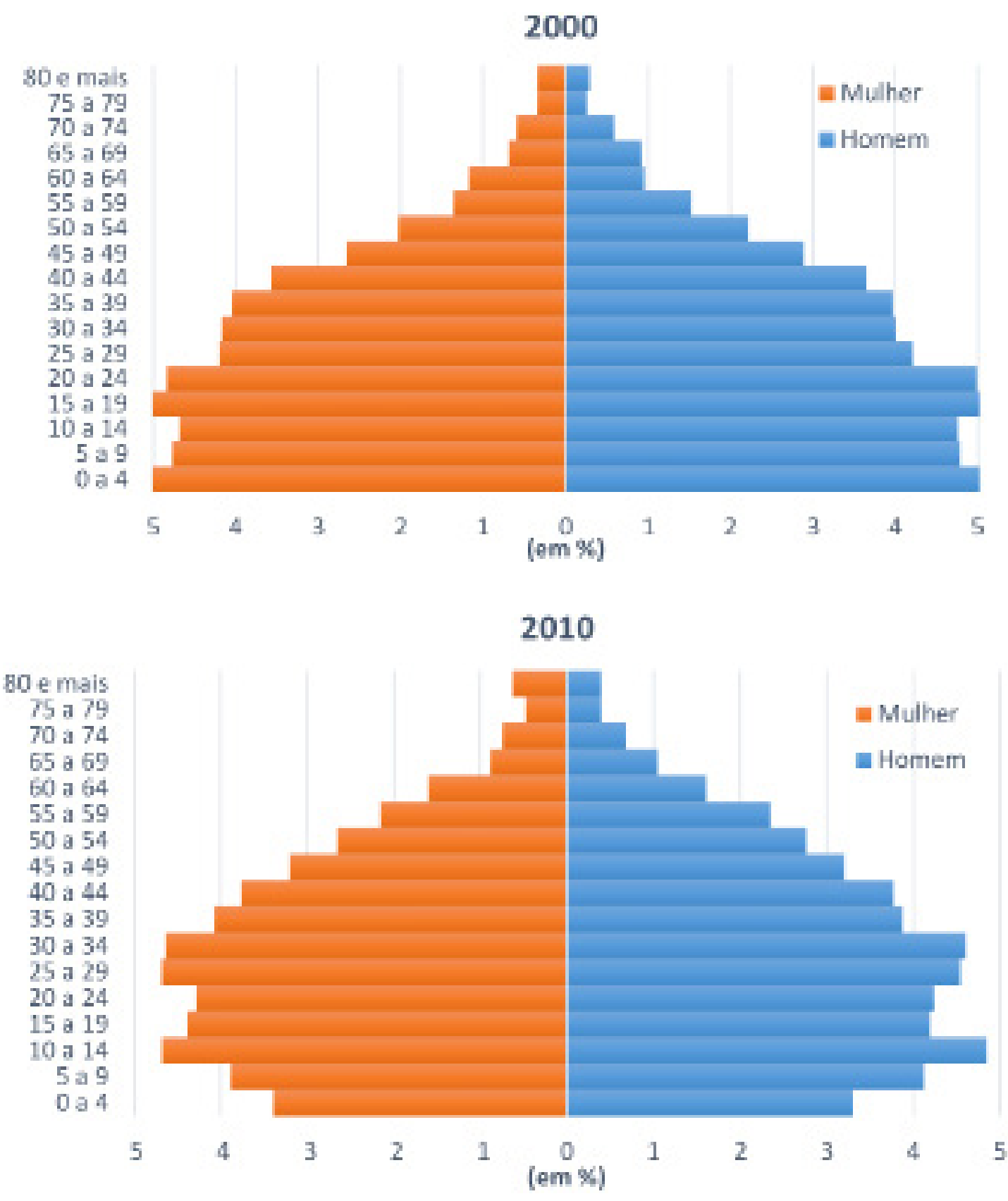

Fonte: IBGE, Censos demográficos.

Apesar do processo de envelhecimento em curso, a proporção de jovens permaneceu ainda muito elevada: em 1980, 37\% da população tinha menos de 15 anos e $60 \%$, menos de 30 anos. Os de menos de 30 anos continuaram a representar $57 \%$ da população em 2000 e ainda mais da metade em 2010. Esta situação foi nada mais do que o resultado do forte movimento migratório das décadas anteriores, que contribuiu para manter uma estrutura da população relativamente jovem, trazendo para cidade imigrantes em sua maioria jovens e portanto em idade reprodutiva. Na década de 1970, por exemplo, $60 \%$ dos migrantes tinham menos de 25 anos. Assim, mesmo em um contexto de forte redução da fecundidade, que passou, de acordo com o IBGE, de 3,6 filhos por mulher em 1980 a 2,8 em 1991 e 2,1 em 2010, a juventude da população permitiu manter a natalidade relativamente elevada: em 2000, a taxa bruta de natalidade de Angra dos Reis era ainda de $23 \%$, cinco pontos a mais do que a média estadual (CEPERJ, 2013). Associada à taxa de mortalidade baixa, isso contribuiu para sustentar o alto nível de crescimento populacional nas últimas décadas e, provavelmente, para alguns anos ainda. 


\section{4- Uma expansão urbana marcada por desigualdades}

O forte crescimento demográfico de Angra dos Reis desde a década de 1950 implicou um intenso processo de urbanização e de adensamento da cidade (Tabela 4). Enquanto em 1950, a população urbana representava apenas um terço da população, ela se tornou majoritária em 1980. Trinta anos depois, Angra dos Reis estava quase totalmente urbanizada, com um grau de urbanização de 96,3\% em 2010. Em paralelo, a densidade residencial média no município aumentou de forma regular no período: de 26 habitantes por km2 em 1950, atinge 104 hab/km2 em 1991 e 205 hab/km2 em 2010.

Tabela 4: População urbana e densidade de população (1950-2010)

\begin{tabular}{|c|c|c|c|c|c|c|c|}
\cline { 2 - 8 } \multicolumn{1}{c|}{} & $\mathbf{1 9 5 0}$ & $\mathbf{1 9 6 0}$ & $\mathbf{1 9 7 0}$ & $\mathbf{1 9 8 0}$ & $\mathbf{1 9 9 1}$ & $\mathbf{2 0 0 0}$ & $\mathbf{2 0 1 0}$ \\
\hline População Urbana (\%) & 33,7 & 46,5 & 47,7 & 50,3 & 91,7 & 95,8 & 96,3 \\
\hline Densidade $\left(\mathrm{hab} / \mathrm{km}^{2}\right)$ & 26 & 35 & 49 & 71 & 104 & 145 & 205 \\
\hline
\end{tabular}

Fonte: IBGE, Censos demográficos.

Entretanto, o crescimento urbano não se deu de maneira contínua e difusa no espaço. A situação geográfica de Angra dos Reis, encravada entre a Baía da Ilha Grande e a Serra do Mar, apresenta uma série de obstáculos físicos para a expansão da cidade, condicionando a um modelo de crescimento fortemente fragmentado a partir dos povoamentos originais isolados localizados ao longo do litoral ${ }^{5}$. A partir dos anos 1970, a abertura da BR101, que atravessa o município, favoreceu a expansão da urbanização e a integração dessas localidades no espaço municipal.

Tabela 5: Taxa de crescimento anual por distritos (1950-2010)

\begin{tabular}{|c|c|c|c|c|c|c|}
\hline Distritos & $\mathbf{1 9 5 0 - 1 9 6 0}$ & $\mathbf{1 9 6 0 - 1 9 7 0}$ & $\mathbf{1 9 7 0 - 1 9 8 0}$ & $\mathbf{1 9 8 0 - 1 9 9 1}$ & $\mathbf{1 9 9 1 - 2 0 0 0}$ & $\mathbf{2 0 0 0 - 2 0 1 0}$ \\
\hline Angra dos Reis - Sede & $6,1 \%$ & $4,0 \%$ & $3,7 \%$ & $1,6 \%$ & $0,4 \%$ & $1,7 \%$ \\
\hline Jacuecanga & $2,2 \%$ & $8,3 \%$ & $3,8 \%$ & $4,8 \%$ & $2,7 \%$ & $3,3 \%$ \\
\hline Cunhambebe & $0,6 \%$ & $4,4 \%$ & $5,1 \%$ & $7,9 \%$ & $6,9 \%$ & $4,8 \%$ \\
\hline Mambucaba & $-1,7 \%$ & $4,3 \%$ & $14,6 \%$ & $7,5 \%$ & $7,0 \%$ & $4,6 \%$ \\
\hline Ilha Grande & $2,0 \%$ & $-1,0 \%$ & $-0,5 \%$ & $-4,2 \%$ & $0,3 \%$ & $0,8 \%$ \\
\hline
\end{tabular}

Fonte: IBGE, Censos demográficos.

Assim, a dinâmica de crescimento não se distribuiu de forma uniforme no espaço (Tabela 5). Em um primeiro momento, o crescimento se concentrou no distrito sede da cidade, que cresceu a um ritmo de 6,1\% por ano na década de 1950, e que reuniu nessa época quase a metade da população da cidade.

Nas décadas seguintes, embora o distrito sede continuasse a apresentar taxas de crescimento significativas até o final dos anos 1970, a dinâmica de crescimento se deslocou para os distritos de Jacuecanga e, em seguida, de Mambucaba e Cunhambebe, onde se localizam os grandes empreendimentos industriais e turísticos implantados na cidade. Esses distritos, durante mais de 40 anos, registraram ritmos de crescimento muito intensos, compreendido entre $4 \%$ e $8 \%$ no período 1960-2000, chegando a culminar a 8\%, em Jacuecanga, na década de 1960 com a abertura do estaleiro Verolme, e a 14\% em Mambucaba no início da construção da usina Angra 1, na década de 1970. Ademais, neste período, o crescimento ultrapassou os limites da cidade como testemunha o ritmo de crescimento elevado de Tarituba nos anos 1970 e 1980, distrito do município vizinho de Parati, adjacente áquele de Mambucaba (CORRÊA, 2012), onde está localizada uma vila residencial de funcionários da Eletronuclear. A partir dos anos 1980, o crescimento acelerado de Cunhambebe e Mambucaba se manteve, diferentemente do distrito de Jacuecanga, que vai apresentar uma desaceleração: no período 1980-2000, o ritmo de crescimento daqueles foram duas vezes mais

5 Assim a vegetação representa mais de 80\% da superfície municipal em 2010 (CORRÊA, 2012). 
rápidos do que o deste último. Desde 1980, mais de dois terços do crescimento total de Angra dos Reis estão se realizando nesses distritos.

Os anos 1980 marcaram igualmente a saturação do distrito central cuja taxa de crescimento caiu para cerca de 1,5\%, provavelmente em razão da escassez de terra e ao custo da moradia, em relação aos outros distritos. De fato, em 2010, o distrito central concentrou apenas $23 \%$ da população da cidade contra $46 \%$ em 1980. Nos anos 1980, observou-se também a acentuação do esvaziamento do distrito da Ilha Grande, com uma da taxa de crescimento negativa de $-4,2 \%$ na década de 1980 , que já apresentava uma diminuição da sua população a partir da década de 1960, em função da decadência da indústria pesqueira. Apesar da expansão da atividade turística neste distrito a partir dos anos 1990, sua ocupação foi controlada por ser uma área de preservação ambiental, limitando seu crescimento.

Esse forte crescimento demográfico de Angra dos Reis correspondeu também a um crescimento ainda mais alto do número de domicílios. Assim, enquanto a população cresceu em torno de 3,5\% por ano entre 1960 e 2010, a taxa de evolução anual média dos domicílios se situou a 5\% no período, e até $6 \%$ entre 1970 e 1980 . Em outros termos, os domicílios aumentaram 1,5 vezes mais rápido do que a população. Esta tendência traduz a diminuição do tamanho dos domicílios. Esta foi particularmente forte ao longo do período, pois o número médio de pessoas por domicilio foi dividido por dois, passando de 5,9 habitantes em 1960 a 3,2 em 2010. Este fenômeno não é surpreendente sendo apenas o reflexo da transição demográfica (diminuição do número de filhos e mudanças de modelo familial) e da estrutura jovem da população, o que favorece a constituição de domicílios de menor tamanho.

Tabela 6: Proporção dos domicílios com acesso as redes de água, luz e esgoto (1950-2010)

\begin{tabular}{|c|c|c|c|c|c|c|c|}
\cline { 2 - 8 } \multicolumn{1}{c|}{} & $\mathbf{1 9 5 0}$ & $\mathbf{1 9 6 0}$ & $\mathbf{1 9 7 0}$ & $\mathbf{1 9 8 0}$ & $\mathbf{1 9 9 1}$ & $\mathbf{2 0 0 0}$ & $\mathbf{2 0 1 0}$ \\
\hline Água & $15,4 \%$ & $24,1 \%$ & $43,4 \%$ & $77,8 \%$ & $84,5 \%$ & $96,6 \%$ & $99,3 \%$ \\
\hline Luz & $17,6 \%$ & $36,2 \%$ & $37,8 \%$ & - & $93,4 \%$ & $98,0 \%$ & $99,7 \%$ \\
\hline Esgoto & $28,7 \%$ & $31,8 \%$ & $32,7 \%$ & $70,6 \%$ & $56,4 \%$ & $78,4 \%$ & $86,4 \%$ \\
\hline
\end{tabular}

Fonte: IBGE, Censos demográficos.

Enfim, assiste-se a melhoria global das condições habitacionais, sendo que os indicadores de acesso dos domicílios à infraestrutura de base (água, luz, esgoto) registram uma progressão constante ao longo dos últimos 50 anos. Assim, em 1950, apenas 15\% dos domicílios estavam conectados à rede de água. Esta percentagem atingiu 78\% em 1980 e, em 2010, a quase totalidade dos domicílios (99,3\%) tinha acesso a este serviço. Da mesma forma, o acesso à rede elétrica se generalizou no período: em 1950, apenas 18\% dos domicílios tinham iluminação elétrica. Em 2010 este serviço era praticamente universal, pois $99,7 \%$ dos domicílios se beneficiavam de energia elétrica. Em comparação o acesso ao saneamento básico permaneceu ainda problemático no município, pois em 2010, somente $86 \%$ dos domicílios tinham esgotamento sanitário adequado (cobertos por rede geral ou fossa séptica). Todavia, observou-se uma nítida melhoria, já que em 1960 menos de um terço dos domicílios tinham uma situação similar, sendo resultado de políticas públicas de saneamento básico, como o programa Prosanear, implantado pela municipalidade a partir de 1992 e que contribuiu para uma expansão significativa da rede de esgoto na década de 1990 (ver Tabela 6).

Ao lado desse quadro de melhoria, deve-se destacar que o processo de urbanização de Angra dos Reis se caracterizou também pelo seu aspecto desigual como atesta a expansão das favelas no espaço urbano, particularmente visíveis nas encostas íngremes do distrito sede. Na ausência de dados históricos permitindo medir a evolução do fenômeno, os dados do Censo 2010 dão uma ideia da sua importância. Entre 2000 e 2010, a população vivendo em aglomerados subnormais cresceu ao mesmo ritmo que a população do município como um todo, a saber 3,7\% por ano. Em 2010, Angra dos Reis contava 37 aglomerados subnormais nos quais vivem mais de 60 mil pessoas, o que representa cerca de $36 \%$ da população total do município (Tabela 7). 
Tabela 7: Número de aglomerados subnormais e população por distritos em 2010

\begin{tabular}{|c|c|c|c|}
\hline Distritos & Número & População em favelas & $\begin{array}{c}\text { População em favelas/População } \\
\text { Total }\end{array}$ \\
\hline Angra dos Reis - Sede & 5 & 6.255 & $16 \%$ \\
\hline Jacuecanga & 12 & 12.460 & $44 \%$ \\
\hline Cunhambebe & 16 & 33.472 & $45 \%$ \\
\hline Mambucaba & 4 & 7.822 & $35 \%$ \\
\hline Ilha Grande & 0 & 0 & $0 \%$ \\
\hline TOTAL & 37 & 60.009 & $36 \%$ \\
\hline
\end{tabular}

Fonte: IBGE, Censo demográfico 2010.

De acordo com os dados apresentados, a presença dos aglomerados subnormais em Angra dos Reis fica restrita à parte continental do município, pois a llha Grande não conta nenhum, embora em graus diferentes segundo os distritos. Isto vem confirmar que o desenvolvimento das favelas é estreitamente relacionado à proximidade com o mercado de trabalho, e no caso de Angra dos Reis, à localização dos grandes empreendimentos turísticos e industriais. A proximidade física entre o local de moradia e o de trabalho é ainda mais determinante, visto o tamanho e a configuração espraiada do município que complica os deslocamentos.

De fato, é o distrito de Cunhambebe que concentra a maior parte das favelas (16) e mais da metade dos habitantes de favelas do município, seguido do distrito de Jacuecanga com 12 favelas e $20 \%$ da população das favelas de Angra dos Reis. Nesses dois distritos, a população favelada é importante, pois corresponde a $45 \%$ da população residente. Eles abrigam também os maiores aglomerados subnormais que chegam a contar entre 1000 e 1500 domicílios. Em comparação, os dois outros distritos, Sede e Mambucaba, apresentam um número relativamente baixo de favelas, mesmo considerando que no caso de Mambucaba, elas reúnem mais de um terço da população do distrito.

\section{5- Considerações Finais}

A dinâmica demográfica de Angra dos Reis se caracterizou por um crescimento particularmente forte e estável a partir dos anos 1950, e suas consequências sobre a expansão espacial e a urbanização da cidade. Os anos 1980 marcaram uma etapa importante na evolução demográfica e espacial de Angra dos Reis. A partir dessa data, a cidade se singularizou no contexto nacional e regional, mantendo um forte crescimento demográfico, enquanto aquele de outros municípios fluminenses diminuí exceto algumas cidades das Baixadas Litorâneas e do Norte Fluminense que se beneficiaram do dinamismo da indústria do petróleo. Esta situação está relacionada ás mudanças que ocorreram nos componentes de crescimento: a partir dos anos 1980, a contribuição da migração para o crescimento, preponderante até então, deixa lugar ao crescimento natural, ele mesmo sendo o produto dos fluxos migratórios anteriores.

No plano espacial, o crescimento urbano se realizou, sobretudo, na parte continental do município, fora do distrito sede, em particular no distrito de Cunhambebe que concentra hoje quase a metade da população total do município. Por um lado, o forte crescimento da cidade se acompanhou de melhoria global das condições habitacionais em termos de acesso dos domicílios ás infraestruturas de base. Por outro lado, o processo de urbanização se deu de forma extremamente desigual como em inúmeras outras cidades brasileiras. Assim, ao longo deste período o município registrou a expansão significativa das favelas, que reúnem hoje mais de um terço da população da cidade.

Apesar desses resultados, o conhecimento sobre as dinâmicas urbanas recentes de Angra dos Reis, suas complexidades e os desafios que elas representam em termos de gestão urbana 
permanece muito insuficiente. Nessa perspectiva, várias frentes de pesquisa se abrem. Os fluxos migratórios, cuja a contribuição foi fundamental no crescimento da cidade, precisam ser melhor compreendidos e analisados. Cabe também aprofundar o estudo das transformações recentes da estrutura do espaço urbano, resultando de 50 anos de crescimento intenso e ininterrupto. De forma mais geral, esse esforço constituirá uma contribuição significativa para a compreensão das cidades médias brasileiras, das suas realidades e das funções que elas desenvolvem na organização do sistema urbano. 


\section{Referências Bibliográficas}

ABREU, Cássio V. Urbanização, apropriação do espaço, conflitos e turismo. Um Estudo de Caso de Angra dos Reis. Dissertação de mestrado em arquitetura e urbanismo. Universidade Federal Fluminense. 2005.

BERTONCELLO, Rodolfo V. Processo de modernização e espaço local: o caso do município de Angra dos Reis $(R J)$. Dissertação de mestrado em geografia. Universidade Federal Fluminense. 1992.

CEPERJ. Anuário Estatístico do Estado do Rio de Janeiro. Fundação Centro Estadual de Estatísticas, Pesquisas e Formação de Servidores Públicos do Rio de Janeiro. Rio de Janeiro: CEPERJ, 2013.

CORRÊA, Renata S. Transformações socioespaciais em Angra dos Reis e Parati (RJ) de 1960/70 a 2010. Dissertação em Geografia. Universidade do Estado do Rio de Janeiro, 2012.

IBGE. Censo Demográfico: 1940. População e habitação. Rio de Janeiro: IBGE, 1940.

IBGE. Censo Demográfico: 1950. Rio de Janeiro: IBGE, 1950.

IBGE. Censo Demográfico: 1960. Rio de Janeiro: IBGE, 1960.

IBGE. Censo Demográfico: 1970. Rio de Janeiro: IBGE, 1970.

IBGE. Censo Demográfico 1980. Microdados da amostra. Rio de Janeiro: IBGE, 1980.

IBGE. Censo Demográfico 1991. Microdados da amostra. Rio de Janeiro: IBGE, 1991.

IBGE. Censo Demográfico 2000. Microdados da amostra. Rio de Janeiro: IBGE, 2000.

IBGE. Censo Demográfico 2010. Microdados da amostra. Rio de Janeiro: IBGE, 2010.

IBGE. Estimativas da população residente nos municípios brasileiros com data de referência em $1^{\circ}$ de julho de 2015. Rio de Janeiro: IBGE, 2015.

OLIVEIRA, Antônio T.R, ERVATTI, Leila R., O'NEILL, Maria M.V.C. “O panorama dos deslocamentos populacionais no Brasil: PNADs e Censos Demográficos". In: OLIVEIRA, L. A.P.; OLIVEIRA, A.T.R. Reflexões sobre os Deslocamentos Populacionais no Brasil. Rio de Janeiro: IBGE, Estudos e Análises 1, 2011.

SANTOS, Luiz A. F. Relações entre território, atividade econômica e migrações -configuração espacial no Município de Angra dos Reis: um foco na escala local - a Vila do Frade. Dissertação em Estudos Populacionais e Pesquisas Sociais, Escola Nacional de Ciências Estatísticas, 2009.

SPOSITO, Maria. E. B. "Cidades médias: reestruturação das cidades e reestruturação urbana". In: SPOSITO, M.E.B (Org.). Cidades médias: espaços em transição. São Paulo: Expressão Popular, 2007, p. 233-253. 